Diyala Journal

ISSN 1999-8716

of Engineering

Printed in Iraq

Sciences

Vol. 06, No. 01, pp. 17-26, March 2013

\title{
COMPARISON OF DIFFERENT UNCONVENTIONAL THERMAL ENERGIES FOR STEEL CUTTING PROCESS
}

\author{
Jasim Hassan Rasheed \\ Department of physics, Science college, University of Diyala \\ (Received:20/10/2011; Accepted:8/1/2012)
}

\begin{abstract}
:- different unconventional heat sources for material processing were discussed. The heat sources such as plasma arc, electron beam and $\mathrm{Co}_{2}$ laser were employed previously by other researchers, while " $\mathrm{Co}_{2}$ laser- gas mixture" system was studied during the present research .

Comparison between the results of present work with the others mentioned above was made . The parameter which was adopted for comparison is the "energy consumed per unit length" for particular thickness. The parameter is based on the equation which was suggested by the author of this research .

Linear relationship between energy per unit length with thickness for $\mathrm{Co}_{2}$ laser alone and "Co 2 laser - gasmixture " was found, while for other heat sources it was found out of the proportionality. This comparison showed the superiority of the " $\mathrm{Co}_{2}$ laser -gas mixture" system over the other heat sources during cutting mild steel.
\end{abstract}

Keywords:- "plasma arc, electron beam , $\mathrm{Co}_{2}$ laser, gas mixture,steel"

\section{INTRODUCTION}

Conventional techniques such as oxy-acetylene and electric arc are used successfully to cut different metals and give reasonable cut quality. However, their thermal energy cannot be concentrated sufficiently to reach the high standard of cutting quality achieved by other means and particularly where a gas jet is used to assist laser cutting by removing debris and assisting the cutting action thermally.

Sullivan and Houldcroft ${ }^{(1)}$ mentioned that using conventional techniques, the width of the cut depends on the width of stream of the oxygen jet. Another disadvantage of using such 
conventional thermal methods is that a large area of the workpiece is heated and is damaged due to thermal distortion and its mechanical properties and structure are adversely affected.

Laser beam, electron beam and plasma techniques allow energy to be concentrated over a fine area in comparison with the area heated by oxy-acetylene and electric-arc methods. The laser beam can be focused to a very small spot and its complete energy can be delivered to the workpiece, providing sufficient energy to evaporate or melt it.

The laser beam is now considered as a good tool for cutting metals, giving very narrow cuts and a narrow heat affected zone which it is impossible to achieve by conventional techniques. The oxygen gas jet can be used in combination with the laser beam to increase the rate of cutting, ${ }^{(2)}$ which is a very important factor, and also the accuracy and quality is not affected by the fact that the cross-sectional area of the stream at the workpiece may be larger than the laser beam cross- section. It can be concluded that the width of the cut is determined basically by the laser beam and not by the gas jet diameter ${ }^{(3)}$, which controls the width of cut in conventional thermal methods.

These phenomena can be explained as follows:

i- The workpiece directly affected by the laser beam is an extremely narrow strip;

ii- The material in this strip heated by laser is raised very rapidly to a temperature at which it melts or vaporizes and there is a very steep temperature gradient in the work piece . Consequently the width of the heat affected zone raised to a temperature high enough to take part in the exothermic reaction is very small.

Because of these advantages, the carbon dioxide laser has been accepted as a good tool for metal cutting over the last few years ${ }^{\cdot(2,4,5,6)}$.

\section{2-MATERIAL PROCESSINGBY}

\section{a- Plasma Torch}

Some manufacturing processes used in modern industrial practice require either high temperatures or intensive heat flow or both. The jet issuing from the plasma torch has a far higher temperature than is required for fusing even the highest melting substances, and on touch it is able to transfer a large amount of heat ${ }^{(7,8)}$. Many metals, such as alloy steel, do not lend themselves to oxygen cutting easily or require costly additives to the cutting flame.

When cutting with plasma torches, the material to be cut is usually one of the electrodes. The plasma jet melts or evaporates the metal, and blows it out of the cut by its 
high rate of discharge ${ }^{(9)}$. Cutting by this method is very rapid and is easily automated. The quality of the cut is good and the material is hardly affected by the heat. Some of the energy produced by plasma torch is wasted to the heat nozzle and electrodes, and also lost as a result of radiation and convection. The effective thermal power of the plasma jet can be adjusted by varying current, voltage, gas flow rate, gas composition, nozzle and nozzle orifice and metal piece surface distance.

The kerf width which occurs when the arc plasma is used is largely determined by the diameter and characteristic of the gas stream ${ }^{(10)}$. Generally speaking, arc cutting requires the removal of material in the molten state. To cut a thick metal sheet efficiently, the width of the cut (i.e. the volume of material lost) has to be kept small and cutting speed high. The high power plasma arc is used as one of the important thermal cutting tools due to its thin gas column and large power density ${ }^{(11)}$.

The high cost of electric current stood in the way of its realization on a large scale until electric power became cheap enough to make the arc an attractive metal cutting tool. The torch offers the following advantages:

i) A stable plasma jet. The stabilizing gas, which blows the arc in the constricted space of the nozzle, ensures a stable direction of the plasma jet and also limits the undesirable travel of the anode spot on the surface of the material. This stabilizing effect, produced even by a relatively small stream of gas, is of prime importance for the quality of the cut surface ${ }^{(12)}$.

ii) High concentration of energy in the plasma jet. This characteristic permits a narrow kerf to be produced at a high cutting speed, and consequently the heat affected zone can be kept quite narrow ${ }^{(7)}$.

iii) The kinetic energy concentrated in the plasma jet causes the molten metal to be promptly blown out from the kerf, hence the cut is clean and free of dross ${ }^{(1)}$.

However, the capital cost, and consequently the cost per linear meter, is higher for plasma torches using argon etc. Plasma torches with air stabilized arc have therefore been developed to reduce the cutting costs on structural steels. The exothermic reaction between atmospheric oxygen and iron increases the cutting rate which may be considered an advantage over the plasma torch stabilized by inert gases.

\section{b- Electron beam}

In metal processing, electrons travel at very high speed and are condensed into a small area at the point of impact with the workpiece. This produces a heat source so intense that 
instantaneous evaporation takes place $(13,14)$. When travelling electrons collide with an object, heat is generated due to conversion of kinetic energy in the electron. This heating effect has undesirable side effects by generating X-rays. The power density of an electron beam focused at a work surface can reach $10 \mathrm{MW} / \mathrm{cm}^{2(15)}$. This can be easily controlled by changing values of focus (spot size), beam current and voltage which depend upon the application requirement.

High energy density beams like electron beams can be used for precise cutting as well as welding. With regard to electron beams, before the development of electron beam welding, drilling and cutting in a vacuum were studied by Arata ${ }^{(10)}$. The author considered applying an electron beam to cutting at atmospheric pressure and succeeded in making combined use of gas dynamic pressure and/or gas reaction energy with these beams, naming them "EB Gas Cutting". EB gas cutting has been studied for cutting rocks rather than metals ${ }^{(16,17)}$.

\section{$\mathrm{C}-\mathrm{CO}_{2}$ laser}

Laser cutting techniques have been studied extensively during the pastdecades, leading to the use of this technique as an attractive heat source in many industrial fields. Mild steel, stainless steel and titanium are the most commonly processed metals due to their importance in the space industry, although laser cutting is generally used for mass production and engineering industries. The laser is also used for materials that are difficult to cut which are characterized by either one or a combination of the following:

i- high melting point

ii- good thermal conductivity

iii- low absorptive

iv- hard metals.

Arata et al ${ }^{(18)}$ reported at an early stage of the laser's development that the cutting of metals by laser beam alone is generally an expensive and slow process because more energy is required to raise the temperature of the surface of the metal above its melting temperature.

In addition losses due to reflection and conduction through the metal's bulk will reduce the amount of energy available for the heating process, leading to inefficiency. Also the molten metal's tend to freeze out on the edge giving a rough cut and very slow cutting speed accompanied with a wide heat affected zone.

Sullivan and Houldcroft ${ }^{(1)}$ were the first to find an effective solution to the above problem. They suggested the use of a reactive gas in conjunction with the laser beam to enhance the cutting process by taking advantage of the exothermic metal/oxygen reaction. 
The gas can also serve to eject the liquid from the metal cut kerf as well as disturbing the plasma and preventing it from building into a thicker layer. The result is that thicker metal may be cut with the laser alone with a relatively small increase in width of cut.

\section{3-EXPERIMENTAL EQUIPMENTS}

For present research the following equipments and materials were used:

a-500(w) $\mathrm{CO}_{2}$ laser (Everlase) system.

b-Gas mixture ( $80 \%$ oxygen and $20 \%$ air) was used coaxially with the $\mathrm{CO}_{2}$ laser beam.

c-Mild steel sheets of different thicknesses were processed.

\section{4- RESULTS AND DISCUSSION}

The results of the present work were obtained by using $\mathrm{CO}_{2}$ laser - gas mixture for cutting mild steel. The results of the other heat sources ( laser beam, electron beam, and plasma arc ) were chosen from literatures which belong to others as shown in table (1) .

Unfortunately, all the previous works of the heat sources mentioned above were done under different parameters such as cutting speed and power. Thus, it is difficult to make direct comparison. To overcome this problem, it is suggested to calculatethe energy consumed per unit length $(\mathrm{J} / \mathrm{mm})$ as following :

Power $(\mathrm{J} / \mathrm{s})$

Energy per unit length $(\mathrm{J} / \mathrm{mm})=$

$$
\text { Speed }(\mathrm{mm} / \mathrm{s})
$$

Figure (1) shows the variation of the energy per unit length with the thickness of the mild steel sheetunder cut processing .Figure (2) shows that the laser - gas mixture combination is the most efficient due to lowest energy per unit length consumed to cut particular thickness.

The superiority of the laser beam - oxygen mixture system is due to exothermic reaction between oxygen gas and metal surface which means more energy produced in addition to the laser power which used for cutting process.

However, laser energy can be deposited by the laser beam directly onto the walls of cut kerf and can also absorbed by the vapor and conducted to the wall . It is well known that the spot size has strong influence on the mechanism of deep penetration due to high power concentrated on a very small area. In relation to the spot size, laser Gaussian power distribution may be used to approximate the power distribution in an electron beam too. 
However, the kerf width which occur when the laser beam and laser - oxygen gas are employed is largely determined by the diameter of the laser beam, while electron beam and plasma are largely determined by the diameter and characteristic of the gas stream. Thus the energy of the laser is concentrated more effectively than the electron beam and plasma arcwhich is another reason for superiority of the laser- oxygen gas system.

\section{5- CONCLUSIONS}

Sheets of mild steel were cut by "CO 2 laser oxygen gas system" during present work. The new results were compared with the results of the previous works for the other heat sources such as plasma arc, electron beam and laser beam.

It was found difficulty to do direct comparison. Therefore, it was suggested by the author of the present research is to calculate the "energy per unit length" consumed for particular thickness by dividing the power employed by cutting speeds which gives excellent results and concluded This calculation is based on the figures attached.

\section{REFERENCES}

1. B. Sullivan and T. Houldcroft "Gas jet laser cutting" Brit. Weld. J . p 443,1967

2. Al- mashikhi and J. powell " laser cutting of thin section of mild steel" J. Appl . phys . v(5), no ,(5),2009.

3. V. Grycz "Plasma technology"ILiff Book 1td, London, 1968.

4. Hilton "The early days of laser cutting processing" $11^{\text {th }}$ conf on laser processing of material, Lappeenranta ,Filand ,2007.

5. H. Kaplan and K. voisey "laser - Oxygen reaction" J. phys ., D. Appl. Phys, $\mathrm{v}(42), \mathrm{p}(11), 2009$.

6. N. Birkett" Laser beam ,electron beam and plasma arc". Mech. Eng. , LoughboroughUniv.Leciestershir , U.k, Report (1-5), 2833/5 , 2009

7. M. Tomsic and C. Jackson "Energy distribution in keyhole mode plasma are welds" welding research supplement v(50), pp(109-113), 1974.

8. M . Cowx " The application of plasma technogy to melting "Tetrcnics and D. Company ltd . lechlade, Faringdon, Oxen , U . K , 2001.

9. M . Mawson"plasma cutting" J.welding and metal fabrication, pp( 298- 302 ) 2003. 
10. M. Mawson " Plasma cutting in industry " welding and metal Fabrication J ., v(2) $\mathrm{p}(15-20), 2004$.

11. A. Engel " Electtic plasma, their nature and uses " International Pulication Services , Taylor and Francis Inc., New York 1983.

12. A. Moss and J. Sheward "The arc plasma cutting " J. phys . D. Appl. Phy.v(22), no (2), 2008.

13. P. Klemens "Heat balance and flow conditions for election and laser beams" J. Appl. Phys . v(47), No (5), pp( 2165 - 2174), 1976.

14. M. Burger and R. Reedy " Temperature distribution produced by electron beam" J.Appl. phys . v(53), No (6) , pp(4357-63), 1982.

15. H. cline "Heat treating with electron beam"J. Appl. Phys. V(48) , pp(3895-3900) ,1977.

16. Y. Arata " Electron and laser beams welding" proceeding first conf . in Tokyo , Japon (14-15) July, 1986.

17. R. B. Hanson " High energy beam ( EB / laser )an overview comparison " J. appl. Phys v (5), 1986.

18. Y. Arata and I. Miyamoto " Some fundamental properties of high Power cw laser beams as a heat sources" Iv/4169 Report, Dept. of welding Eng. Osaka Univ. Japan 1972. 
Table (1):Comparison of different heat sources .

1- Electron beam $(12,20)$ Speed $(\mathrm{v})=7 \mathrm{~mm} / \mathrm{sec}$

\begin{tabular}{|c|c|c|}
\hline $\begin{array}{c}\text { Thickness } \\
(\mathrm{mm}), \mathrm{ts}\end{array}$ & $\begin{array}{c}\text { Power } \\
(\mathrm{w}), \mathrm{p}\end{array}$ & $\begin{array}{c}\text { Energy /length } \\
(\mathrm{J} / \mathrm{mm})=\mathrm{p} / \mathrm{v}\end{array}$ \\
\hline 0.5 & 220 & 31.4 \\
\hline 1.0 & 300 & 43 \\
\hline 1.5 & 480 & 68.6 \\
\hline 2 & 720 & 103 \\
\hline 2.5 & 1000 & 143 \\
\hline
\end{tabular}

Plasma arc $(13,15,20)$, speed $(\mathrm{v})=4 \mathrm{~mm} / \mathrm{sec}$.

\begin{tabular}{|c|c|c|}
\hline $\begin{array}{c}\text { Thickness } \\
(\mathrm{mm}), \mathrm{ts}\end{array}$ & $\begin{array}{c}\text { Power } \\
(\mathrm{w}), \mathrm{p}\end{array}$ & $\begin{array}{c}\text { Energy /length } \\
(\mathrm{J} / \mathrm{mm})=\mathrm{p} / \mathrm{v}\end{array}$ \\
\hline 0.5 & 320 & 80 \\
\hline 1.0 & 420 & 105 \\
\hline 1.5 & 540 & 136 \\
\hline 2 & 720 & 180 \\
\hline 2.5 & 960 & 240 \\
\hline
\end{tabular}

$\mathrm{CO} 2$ laser $(12,20)$ speed $(\mathrm{v})=9 \mathrm{~mm} / \mathrm{sec}$.

\begin{tabular}{|c|c|c|}
\hline $\begin{array}{c}\text { Thickness } \\
(\mathrm{mm}), \mathrm{ts}\end{array}$ & $\begin{array}{c}\text { Power } \\
(\mathrm{w}), \mathrm{p}\end{array}$ & $\begin{array}{c}\text { Energy /length } \\
(\mathrm{J} / \mathrm{mm})=\mathrm{p} / \mathrm{v}\end{array}$ \\
\hline 0.5 & 240 & 27.6 \\
\hline 1.0 & 340 & 38 \\
\hline 1.5 & 410 & 46 \\
\hline 2 & 510 & 58 \\
\hline 2.5 & 620 & 69 \\
\hline
\end{tabular}

$\mathrm{CO}_{2}$ laser - gas mixture ( present work) speed $(\mathrm{v})=8 \mathrm{~mm} / \mathrm{sec}$.

\begin{tabular}{|c|c|c|}
\hline $\begin{array}{c}\text { Thickness } \\
(\mathrm{mm}), \mathrm{ts}\end{array}$ & $\begin{array}{c}\text { Power } \\
(\mathrm{w}), \mathrm{p}\end{array}$ & $\begin{array}{c}\text { Energy /length } \\
(\mathrm{J} / \mathrm{mm})=\mathrm{p} / \mathrm{v}\end{array}$ \\
\hline 0.5 & 120 & 15 \\
\hline 1.0 & 184 & 23 \\
\hline 1.5 & 275 & 34 \\
\hline 2 & 355 & 44 \\
\hline 2.5 & 470 & 61 \\
\hline
\end{tabular}




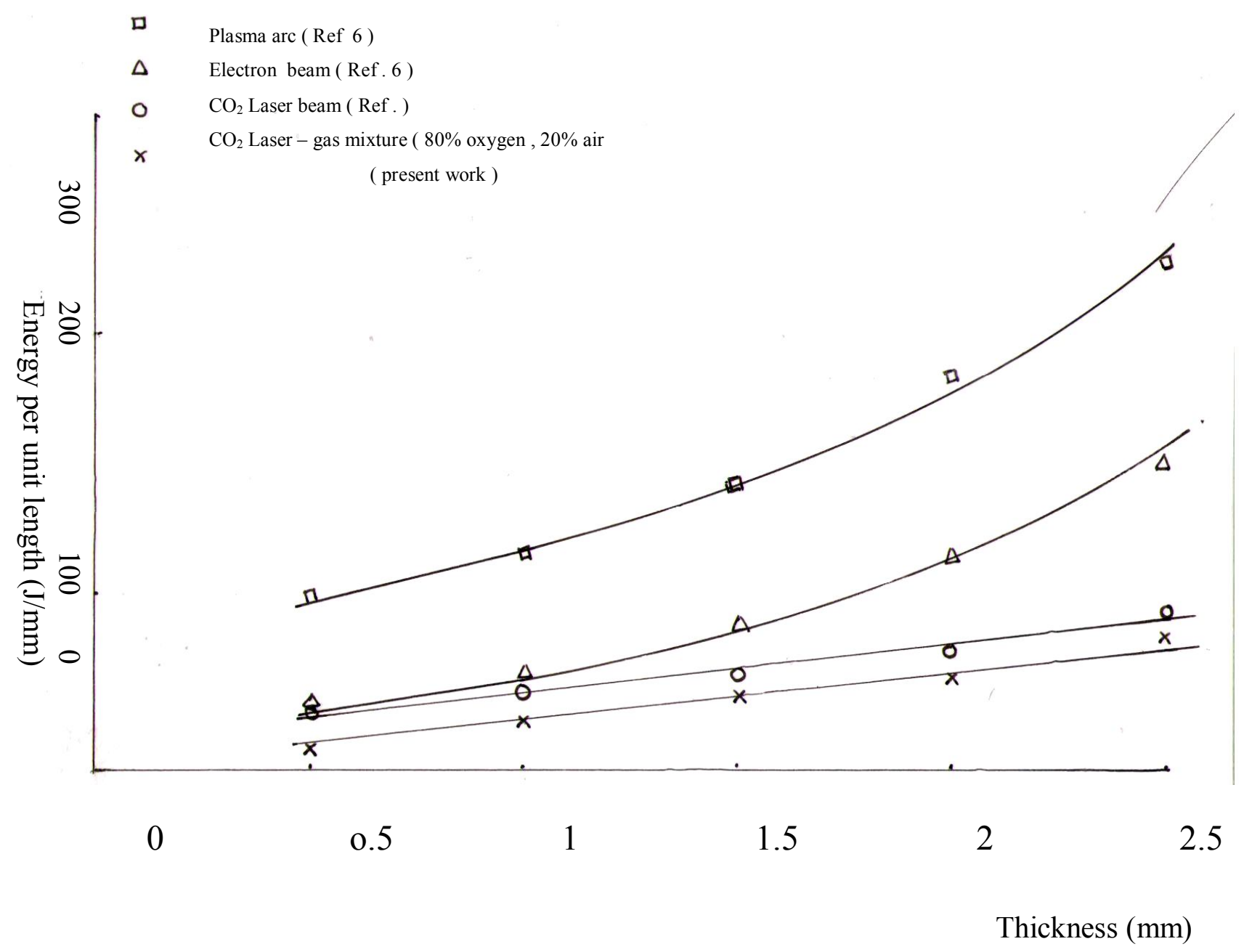

Fig. (1 ): variation of energy per unit length thickness. 


\title{
مقارنة مصادر طاقة حرارية غير تقليدية في عملية قطع الفولاذ
}

\author{
جاسم حسن رشيد \\ مدرس \\ كلية العلوم _جامعة ديالى مدري
}

الخلاصة

تمت مناقثة المصادر الحرارية غير التقليدية المستخدمة في معالجة المواد حراريا وهذه المصادر الحرارية هي

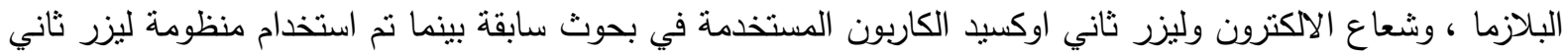

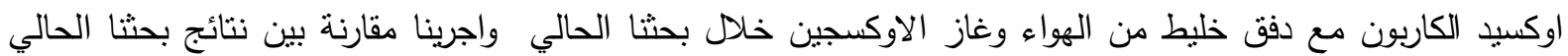
والسابقة وان العامل الذي تمت حسابات المقارنة على ضوئه" الطاقة المصروفة لوحدة الطول " ولسمك معين . ان هذا العامل قد اسس على معادلة مقترحة من قبل صاحب هذا البحث ، لقد وجدنا علاقة خطية بين الطاقة المصروفة لوحدة الطول ولسمك معين بالنسبة للمصدرين ليزر ثاني اوكسيد الكاربون ومنظومة "ليزر ثاني اوكسيد الكاربون - وخليط الغاز" • بينما كانت العلاقة غير خطية بالنسبة للمصادر الحرارية الاخرى، لقد اظهر هذا البحث افضلية

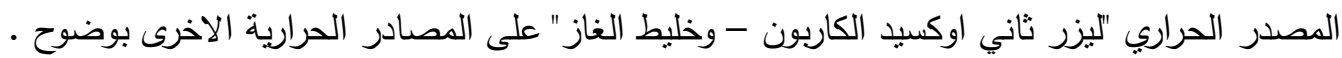

